\title{
Multiple Solutions of Second-Order Damped Impulsive Differential Equations with Mixed Boundary Conditions
}

\author{
Jian Liu ${ }^{1}$ and Lizhao Yan $^{2}$ \\ ${ }^{1}$ School of Economics and Management, Changsha University of Science and Technology, Changsha, Hunan 410004, China \\ ${ }^{2}$ Hunan Normal University Press, Hunan Normal University, Changsha, Hunan 410081, China
}

Correspondence should be addressed to Lizhao Yan; yanbine@126.com

Received 14 February 2014; Accepted 27 March 2014; Published 23 April 2014

Academic Editor: Fenghua Wen

Copyright (C) 2014 J. Liu and L. Yan. This is an open access article distributed under the Creative Commons Attribution License, which permits unrestricted use, distribution, and reproduction in any medium, provided the original work is properly cited.

We use variational methods to investigate the solutions of damped impulsive differential equations with mixed boundary conditions. The conditions for the multiplicity of solutions are established. The main results are also demonstrated with examples.

\section{Introduction}

Impulsive effect exists widely in many evolution processes in which their states are changed abruptly at certain moments of time. The theory of impulsive differential systems has been developed by numerous mathematicians [1-6]. Applications of impulsive differential equations with or without delays occur in biology, medicine, mechanics, engineering, chaos theory, and so on [7-11].

In this paper, we consider the following second-order damped impulsive differential equations with mixed boundary conditions:

$$
\begin{array}{r}
-u^{\prime \prime}(t)+g(t) u^{\prime}(t)-\lambda u(t)=f(t, u(t)), \\
t \neq t_{j}, \quad \text { a.e. } t \in[0, T], \\
-\Delta u^{\prime}\left(t_{j}\right)=I_{j}\left(u\left(t_{j}\right)\right), \quad j=1,2, \ldots, n, \\
u^{\prime}(0)=0, \quad u(T)=0,
\end{array}
$$

where $0=t_{0}<t_{1}<t_{2}<\cdots<t_{n}<t_{n+1}=T, g \in C[0, T]$, $f:[0, T] \times R \rightarrow R$ is continuous, $I_{j}: R \rightarrow R, j=1,2, \ldots, n$ are continuous, and $\Delta u^{\prime}\left(t_{j}\right)=u^{\prime}\left(t_{j}^{+}\right)-u^{\prime}\left(t_{j}^{-}\right)$for $u^{\prime}\left(t_{j}^{ \pm}\right)=$ $\lim _{t \rightarrow t_{j}^{ \pm}} u^{\prime}(t), j=1,2, \ldots, n$.

The characteristic of (1) is the presence of the damped term $g(t) u^{\prime}$. Most of the results concerning the existence of solutions of these equations are obtained using upper and lower solutions methods, coincidence degree theory, and fixed point theorems [12-15]. On the other hand, when there is no presence of the damped term, some researchers have used variational methods to study the existence of solutions for these problems [16-21]. However, to the best of our knowledge, there are few papers concerned with the existence of solutions for impulsive boundary value problems like problem (1) by using variational methods.

For this nonlinear damped mixed boundary problem (1), the variational structure due to the presence of the damped term $g(t) u^{\prime}$ is not apparent. However, inspired by the work $[22,23]$, we will be able to transform it into a variational formulation. In this paper, our aim is to study the existence of $n$ distinct pairs of nontrivial solutions of problem (1). Our main results extend the study made in $[22,23]$, in the sense that we deal with a class of problems that is not considered in those papers.

\section{Preliminaries and Statements}

Let $m=\min _{t \in[0, T]} e^{G(t)}, M=\max _{t \in[0, T]} e^{G(t)}, G(t)=$ $-\int_{0}^{t} g(s) d s, t \in[0, T]$. We transform (1) into the following equivalent form:

$$
\begin{array}{r}
-\left(e^{G(t)} u^{\prime}(t)\right)^{\prime}-\lambda e^{G(t)} u(t)=e^{G(t)} f(t, u(t)), \\
t \neq t_{j}, \quad \text { a.e. } t \in[0, T]
\end{array}
$$




$$
\begin{gathered}
-\Delta u^{\prime}\left(t_{j}\right)=I_{j}\left(u\left(t_{j}\right)\right), \quad j=1,2, \ldots, n, \\
u^{\prime}(0)=0, u(T)=0 .
\end{gathered}
$$

Obviously, the solutions of (2) are solutions of (1).

Define the space $X=\{u(t) \quad \mid u(t)$ is absolutely continuous on $\left.[0, T], u^{\prime}(\cdot) \in L^{2}[0, T], u(T)=0\right\}$. It is easy to see that $H_{0}^{1}(0, T) \subset X \subset H^{1}(0, T)$ and $X$ is a closed subset of $H^{1}(0, T)$. So $X$ is a Hilbert space with the usual inner product in $H^{1}(0, T)$.

Consider the Hilbert spaces $X$ with the inner product

$$
(u, v)=\int_{0}^{T} e^{G(t)} u^{\prime}(t) v^{\prime}(t) d t
$$

inducing the norm

$$
\|u\|=\left(\int_{0}^{T} e^{G(t)}\left|u^{\prime}(t)\right|^{2} d t\right)^{1 / 2} .
$$

We also consider the inner product

$$
(u, v)=\int_{0}^{T} u^{\prime}(t) v^{\prime}(t) d t
$$

inducing the norm

$$
\|u\|_{X}=\left(\int_{0}^{T}\left|u^{\prime}(t)\right|^{2} d t\right)^{1 / 2} .
$$

Consider the problem

$$
\begin{gathered}
-u^{\prime \prime}(t)=\lambda u(t), \quad t \in[0, T], \\
u^{\prime}(0)=0, \quad u(T)=0 .
\end{gathered}
$$

As is well known, (7) possesses a sequence of eigenvalues $\left(\lambda_{i}\right)\left(\lambda_{i}=[(2 i-1) \pi / 2 T]^{2}\right)$ with

$$
0<\lambda_{1}<\lambda_{2}<\cdots<\lambda_{j}<\cdots .
$$

The corresponding eigenfunctions are normalized so that $\left\|\varphi_{j}\right\|_{X}=1=\lambda_{j} \int_{0}^{T}\left|\varphi_{j}(t)\right|^{2} d t$; here

$$
\varphi_{j}(t)=\sqrt{\frac{2}{T \lambda_{j}}} \cos \left(\sqrt{\lambda_{j}} t\right), \quad j=1,2, \ldots
$$

Now multiply (2) by $v \in X$ and integrate on the interval $[0, T]:$

$$
\begin{aligned}
& \int_{0}^{T} e^{G(t)} u^{\prime}(t) v^{\prime}(t) d t-\lambda \int_{0}^{T} e^{G(t)} u(t) v(t) d t \\
& =\sum_{j=1}^{n} e^{G\left(t_{j}\right)} I_{j}\left(u\left(t_{j}\right)\right) v\left(t_{j}\right)+\int_{0}^{T} e^{G(t)} f(t, u(t)) v(t) d t .
\end{aligned}
$$

Then, a weak solution of (2) is a critical point of the following functional:

$$
\begin{aligned}
E(u)= & \frac{1}{2} \int_{0}^{T} e^{G(t)}\left|u^{\prime}(t)\right|^{2} d t-\frac{\lambda}{2} \int_{0}^{T} e^{G(t)}|u(t)|^{2} d t \\
& -\sum_{j=1}^{n} e^{G\left(t_{j}\right)} \int_{0}^{u\left(t_{j}\right)} I_{j}(t) d t-\int_{0}^{T} e^{G(t)} F(t, u(t)) d t,
\end{aligned}
$$

where $F(t, u)=\int_{0}^{u} f(t, \xi) d \xi$.

We say that $u \in C[0, T]$ is a classical solution of IBVP (1) if it satisfies the following conditions: $u$ satisfies the first equation of (1) a.e. on $[0, T]$; the limits $u^{\prime}\left(t_{j}^{+}\right), u^{\prime}\left(t_{j}^{-}\right)$, $j=1,2, \ldots, n$, exist and impulsive condition of (1) holds; $u$ satisfies the boundary condition of (1).

Lemma 1. If $u \in X$ is a weak solution of (1), then $u$ is a classical solution of (1).

Proof. If $u \in X$ is a weak solution of (1), then $u$ is a weak solution of (2), so $\left(E^{\prime}(u), v\right)=0$ holds for all $v \in X$; that is,

$$
\begin{gathered}
\int_{0}^{T}\left[e^{G(t)} u^{\prime}(t) v^{\prime}(t)+\lambda e^{G(t)} u(t) v(t)\right] d t \\
-\sum_{j=1}^{n} e^{G\left(t_{j}\right)} I_{j}\left(u\left(t_{j}\right)\right) v\left(t_{j}\right) \\
-\int_{0}^{T} e^{G(t)} f(t, u(t)) v(t) d t=0 .
\end{gathered}
$$

By integrating by part, we have

$$
\begin{aligned}
\int_{0}^{T} & {\left[e^{G(t)} u^{\prime}(t) v^{\prime}(t)+\lambda e^{G(t)} u(t) v(t)\right] d t } \\
& -\sum_{j=1}^{n} e^{G\left(t_{j}\right)} I_{j}\left(u\left(t_{j}\right)\right) v\left(t_{j}\right) \\
& -\int_{0}^{T} e^{G(t)} f(t, u(t)) v(t) d t \\
= & \int_{0}^{T}\left[-\left(e^{G(t)} u^{\prime}(t)\right)^{\prime}+\lambda e^{G(t)} u(t)-e^{G(t)} f(t, u(t))\right] v(t) d t \\
& -\sum_{j=1}^{n} e^{G\left(t_{j}\right)}\left[\Delta u^{\prime}\left(t_{j}\right)+I_{j}\left(u\left(t_{j}\right)\right)\right] v\left(t_{j}\right) \\
& -e^{G(0)} u^{\prime}(0) v(0)+e^{G(T)} u^{\prime}(T) v(T) \\
= & \int_{0}^{T}\left[-\left(e^{G(t)} u^{\prime}(t)\right)^{\prime}+\lambda e^{G(t)} u(t)-e^{G(t)} f(t, u(t))\right] v(t) d t \\
& -\sum_{j=1}^{n} e^{G\left(t_{j}\right)}\left[\Delta u^{\prime}\left(t_{j}\right)+I_{j}\left(u\left(t_{j}\right)\right)\right] v\left(t_{j}\right)-u^{\prime}(0) v(0) .
\end{aligned}
$$


Thus

$$
\begin{aligned}
& \int_{0}^{T}\left[-\left(e^{G(t)} u^{\prime}(t)\right)^{\prime}+\lambda e^{G(t)} u(t)-e^{G(t)} f(t, u(t))\right] v(t) d t \\
& -\sum_{j=1}^{n} e^{G\left(t_{j}\right)}\left[\Delta u^{\prime}\left(t_{j}\right)+I_{j}\left(u\left(t_{j}\right)\right)\right] v\left(t_{j}\right) \\
& -u^{\prime}(0) v(0)=0
\end{aligned}
$$

holds for all $v \in X$. Without loss of generality, for any $j=$ $\{1,2, \ldots, n\}$ and $v \in X$ with $v(t) \equiv 0$, for every $t \in\left[0, t_{j}\right] \cup$ $\left[t_{j+1}, T\right]$, then substituting $v$ into (14), we get

$$
\begin{array}{r}
-\left(e^{G(t)} u^{\prime}(t)\right)^{\prime}+\lambda e^{G(t)} u(t)-e^{G(t)} f(t, u(t))=0, \\
t \in\left(t_{j}, t_{j+1}\right) .
\end{array}
$$

Hence $u$ satisfies the first equation of (2). Therefore, by (14) we have

$$
-\sum_{j=1}^{n} e^{G\left(t_{j}\right)}\left[\Delta u^{\prime}\left(t_{j}\right)+I_{j}\left(u\left(t_{j}\right)\right)\right] v\left(t_{j}\right)-u^{\prime}(0) v(0)=0 .
$$

Next we will show that $u$ satisfies the impulsive and the boundary condition in (2). If the impulsive condition in (2) does not hold, without loss of generality, we assume that there exists $j \in\{1,2, \ldots, n\}$ such that

$$
\Delta u^{\prime}\left(t_{j}\right)+I_{j}\left(u\left(t_{j}\right)\right) \neq 0
$$

Let $v(t)=\prod_{i=0, i \neq j}^{n+1}\left(t-t_{i}\right)$; then

$$
\begin{gathered}
-\sum_{j=1}^{n} e^{G\left(t_{j}\right)}\left[\Delta u^{\prime}\left(t_{j}\right)+I_{j}\left(u\left(t_{j}\right)\right)\right] v\left(t_{j}\right)-u^{\prime}(0) v(0) \\
=-e^{G\left(t_{j}\right)}\left[\Delta u^{\prime}\left(t_{j}\right)+I_{j}\left(u\left(t_{j}\right)\right)\right] v\left(t_{j}\right) \neq 0,
\end{gathered}
$$

which contradicts (16). So $u$ satisfies the impulsive condition in (2) and (16) implies

$$
u^{\prime}(0) v(0)=0 \text {. }
$$

If $u^{\prime}(0) \neq 0$, pick $v(t)=\prod_{i=1}^{n+1}\left(t-t_{i}\right)$; one has

$$
u^{\prime}(0) \prod_{i=1}^{n+1}\left(t_{0}-t_{i}\right) \neq 0,
$$

which contradicts (19), so $u$ satisfies the boundary condition. Therefore, $u$ is a solution of (1).

Lemma 2. Let $u \in X$. Then there exists a constant $\sigma>0$, such that

$$
\|u\|_{\infty} \leq \sigma\|u\|
$$

where $\|u\|_{\infty}=\max _{t \in[0, T]}|u(t)|$.
Proof. By Hölder inequality, for $u \in X$,

$$
\begin{aligned}
|u(t)| & =\left|u(T)-\int_{t}^{T} u^{\prime}(s) d s\right| \\
& \leq\left(\int_{0}^{T} \frac{1}{e^{G(s)}} d s\right)^{1 / 2}\left(\int_{0}^{T} e^{G(s)}\left|u^{\prime}(s)\right|^{2} d s\right)^{1 / 2} \\
& \leq \sqrt{\frac{T}{m}}\|u\|=\sigma\|u\| .
\end{aligned}
$$

Lemma 3 (see [24, Theorem 9.1]). Let E be a real Banach space, $I \in C^{1}(E, R)$ with I even, bounded from below, and satisfying P.S. condition. Suppose $I(0)=0$; there is a set $K \subset E$ such that $K$ is homeomorphic to $S^{j-1}$ by an odd map and $\sup _{K} I<0$. Then I possesses at least $j$ distinct pairs of critical points.

\section{Main Results}

Theorem 4. Suppose that the following conditions hold.

(H1) There exist $u_{1}>0, r>M \lambda_{k} / m, \lambda_{k}$ which is the kth eigenvalue of (7) such that

$$
\begin{array}{r}
r M u_{1}+e^{G(t)} f\left(t, u_{1}\right)=0, \quad r M u_{1}+e^{G(t)} f(t, u)>0 \\
\text { for every } u \in\left(0, u_{1}\right) .
\end{array}
$$

(H2) There exist $a_{j}, b_{j}>0$ and $r_{j} \in[0,1)(j=1,2, \ldots, n)$ such that

$$
\left|I_{j}(u)\right| \leq a_{j}+b_{j}|u|^{r_{j}} \quad \text { for any } u \in R
$$

(H3) $f(t, u)$ and $I_{j}(u)(j=1,2, \ldots, n)$ are odd about $u$.

$(\mathrm{H} 4) f(t, u)=o(|u|), I_{j}(u)=o(|u|)$, as $|u| \rightarrow 0, j=$ $1,2, \ldots, n$.

Then, for $\lambda \in\left(M \lambda_{k} / m, r\right]$, problem (1) has at least $k$ distinct pairs of solutions.

Proof. Set

$$
h_{1}(\lambda, t, u)= \begin{cases}\lambda e^{G(t)} u+e^{G(t)} f(t, u) & u \in\left[-u_{1}, u_{1}\right], \\ \lambda e^{G(t)} u_{1}+e^{G(t)} f\left(t, u_{1}\right), & u \in\left[u_{1},+\infty\right), \\ -\lambda e^{G(t)} u_{1}-e^{G(t)} f\left(t,-u_{1}\right), & u \in\left(-\infty,-u_{1}\right] .\end{cases}
$$

Consider

$$
\begin{gathered}
-\left(e^{G(t)} u^{\prime}(t)\right)^{\prime}=h_{1}(\lambda, t, u(t)), \\
t \neq t_{j}, \quad \text { a.e. } t \in[0, T], \\
-\Delta u^{\prime}\left(t_{j}\right)=I_{j}\left(u\left(t_{j}\right)\right), \quad j=1,2, \ldots, n, \\
u^{\prime}(0)=0, \quad u(T)=0 .
\end{gathered}
$$


Next, we will verify that the solutions of problem (26) are solutions of problem (1).

In fact, let $u_{0}(t)$ be the solution of problem (26). If $\max _{0 \leq t \leq T} u_{0}(t)>u_{1}$, then there exists an interval $[a, b] \subset$ $[0, T]$ such that

$$
u_{0}(a)=u_{0}(b)=u_{1}, \quad u_{0}(t)>u_{1} \quad \text { for any } t \in(a, b) .
$$

When $t \in[a, b]$, by (H1), we have

$$
\begin{aligned}
-\left(e^{G(t)} u_{0}^{\prime}(t)\right)^{\prime}= & h_{1}(\lambda, t, u) \\
= & \lambda e^{G(t)} u_{1}+e^{G(t)} f\left(t, u_{1}\right) \leq r M u_{1} \\
& +e^{G(t)} f\left(t, u_{1}\right)=0
\end{aligned}
$$

That is, $e^{G(t)} u_{0}^{\prime}(t)$ is nondecreasing in $[a, b]$. By $u_{0}^{\prime}(a) \geq 0$ and $u_{0}^{\prime}(b) \leq 0$, we have

$$
\begin{array}{r}
0 \leq e^{G(t)} u_{0}^{\prime}(a) \leq e^{G(t)} u_{0}^{\prime}(t) \leq e^{G(t)} u_{0}^{\prime}(b) \leq 0 \\
\text { for every } t \in[a, b] .
\end{array}
$$

That is, $e^{G(t)} u_{0}^{\prime}(t) \equiv 0$ for any $t \in[a, b]$. Since $e^{G(t)} \neq 0$, then $u_{0}^{\prime}(t) \equiv 0$. So, there exists a constant $\epsilon$ such that $u_{0}(t) \equiv \epsilon$, which contradicts (27). Then $\max _{0 \leq t \leq T} u_{0}(t) \leq u_{1}$. Similarly, we can prove that $\min _{0 \leq t \leq T} u_{0}(t)>-u_{1}$.

Therefore, any solution of (26) is a solution of (1). Hence to prove Theorem 4 , it suffices to produce at least $k$ distinct pairs of critical points of

$$
\begin{aligned}
E_{1}(u)= & \frac{1}{2} \int_{0}^{T} e^{G(t)}\left|u^{\prime}(t)\right|^{2} d t-\int_{0}^{T} H_{1}(\lambda, t, u(t)) d t \\
& -\sum_{j=1}^{n} e^{G\left(t_{j}\right)} \int_{0}^{u\left(t_{j}\right)} I_{j}(t) d t,
\end{aligned}
$$

where $H_{1}(\lambda, t, u(t))=\int_{0}^{u} h_{1}(\lambda, t, s) d s$.

We will apply Lemma 3 to finish the proof.

By (30) and (H3), $E_{1} \in C^{\prime}(X, R)$ is even and $E_{1}(0)=0$.

Next, we will show that $E_{1}$ is bounded from below.

Let $C_{1}=\max \left\{a_{1}, a_{2}, \ldots, a_{n}\right\}, C_{2}=\max \left\{b_{1}, b_{2}, \ldots, b_{n}\right\}$. By (H1) and (H3), we have $u h_{1}(\lambda, t, u(t)) \leq 0$ for $|u| \geq u_{1}$; thus

$$
\begin{aligned}
\int_{0}^{T} H_{1}(\lambda, t, u(t)) d t & =\int_{0}^{T} \int_{0}^{u(t)} h_{1}(\lambda, t, s) d s d t \\
& \leq \int_{0}^{T} \int_{0}^{u_{1}} h_{1}(\lambda, t, s) d s d t \\
& \leq \int_{0}^{T} \int_{0}^{u_{1}}[r M s+f(t, s)] d s d t=\rho>0 .
\end{aligned}
$$

So, we have

$$
\begin{aligned}
E_{1}(u)= & \frac{1}{2}\|u\|^{2}-\int_{0}^{T} H_{1}(\lambda, t, u(t)) d t \\
& -\sum_{j=1}^{n} e^{G\left(t_{j}\right)} \int_{0}^{u\left(t_{j}\right)} I_{j}(t) d t \\
\geq & \frac{1}{2}\|u\|^{2}-\rho-n \sigma C_{1} M\|u\|-C_{2} M \sum_{j=1}^{n} \sigma^{r_{j}+1}\|u\|^{r_{j}+1} \\
> & -\infty,
\end{aligned}
$$

for any $u \in X$. Therefore, $E_{1}$ is bounded from below.

In the following we will show that $E_{1}$ satisfies the P.S. condition. Let $\left\{u_{k}\right\} \subset X$ such that $\left\{E_{1}\left(u_{k}\right)\right\}$ is a bounded sequence and $\lim _{k \rightarrow \infty} E_{1}^{\prime}\left(u_{k}\right)=0$; then there exists $C_{3}>0$ such that

$$
\left|E_{1}\left(u_{k}\right)\right| \leq C_{3} .
$$

By (32), we have

$$
\begin{aligned}
\frac{1}{2}\left\|u_{k}\right\|^{2} \leq & C_{3}+\rho+n \sigma C_{1} M\left\|u_{k}\right\| \\
& +C_{2} M \sum_{j=1}^{n} \sigma^{r_{j}+1}\|u\|^{r_{j}+1} .
\end{aligned}
$$

So $\left\{u_{k}\right\}$ is bounded in $X$. From the reflexivity of $X$, we may extract a weakly convergent subsequence that, for simplicity, we call $\left\{u_{k}\right\}, u_{k} \rightarrow u$ in $X$. In the following we will verify that $\left\{u_{k}\right\}$ strongly converges to $u$ :

$$
\begin{aligned}
& \left(E_{1}^{\prime}\left(u_{k}\right)-E_{1}^{\prime}(u)\right)\left(u_{k}-u\right) \\
& =\left\|u_{k}-u\right\|^{2}-\int_{0}^{T}\left[h_{1}\left(\lambda, t, u_{k}(t)\right)-h_{1}(\lambda, t, u(t))\right] \\
& \quad \times\left(u_{k}(t)-u(t)\right) d t \\
& +\sum_{j=1}^{n} e^{G\left(t_{j}\right)}\left[I_{j}\left(u_{k}\left(t_{j}\right)\right)-I_{j}\left(u\left(t_{j}\right)\right)\right] \\
& \quad \times\left(u_{k}\left(t_{j}\right)-u\left(t_{j}\right)\right) .
\end{aligned}
$$

By $u_{k} \rightarrow u$ in $X$, we see that $\left\{u_{k}\right\}$ uniformly converges to $u$ in $C[0, T]$. So

$$
\begin{gathered}
\int_{0}^{T}\left[h_{1}\left(\lambda, t, u_{k}(t)\right)-h_{1}(\lambda, t, u(t))\right] \\
\times\left(u_{k}(t)-u(t)\right) d t \rightarrow 0, \\
\sum_{j=1}^{n} e^{G\left(t_{j}\right)}\left[I_{j}\left(u_{k}\left(t_{j}\right)\right)-I_{j}\left(u\left(t_{j}\right)\right)\right] \\
\times\left(u_{k}\left(t_{j}\right)-u\left(t_{j}\right)\right) \longrightarrow 0, \\
\left(E_{1}^{\prime}\left(u_{k}\right)-E_{1}^{\prime}(u)\right)\left(u_{k}-u\right) \longrightarrow 0, \text { as } k \longrightarrow+\infty .
\end{gathered}
$$


So we obtain $\left\|u_{k}-u\right\| \rightarrow 0$, as $k \rightarrow+\infty$. That is, $\left\{u_{k}\right\}$ strongly converges to $u$ in $X$, which means that $E_{1}$ satisfies the P.S. condition.

Now set $K=\left\{\sum_{i=1}^{k} c_{i} \varphi_{i}: \sum_{i=1}^{k} c_{i}^{2}=c^{2}\right\}$, where $\varphi_{i}$ is defined in (9). It is clear that $K$ is homeomorphic to $S^{k-1}$ by an odd map for any $c>0$. In the following we verify that $\left.E_{1}\right|_{K}<0$ if $c$ is sufficiently small.

For any $u \in K, u=\sum_{i=1}^{k} c_{i} \varphi_{i}$. By (H4) and (30), we have

$$
\begin{aligned}
& E_{1}(u)=\frac{1}{2} \int_{0}^{T} e^{G(t)}\left[\left(\sum_{i=1}^{k} c_{i} \varphi_{i}(t)\right)^{\prime}\right]^{2} d t \\
& -\int_{0}^{T} H_{1}(\lambda, t, u(t)) d t \\
& -\sum_{j=1}^{n} e^{G\left(t_{j}\right)} \int_{0}^{u\left(t_{j}\right)} I_{j}(t) d t \\
& =\frac{1}{2} \sum_{i=1}^{k} c_{i}^{2} \int_{0}^{T} e^{G(t)}\left[\varphi_{i}^{\prime}(t)\right]^{2} d t \\
& -\frac{\lambda}{2} \sum_{i=1}^{k} c_{i}^{2} \int_{0}^{T} e^{G(t)}\left[\varphi_{i}(t)\right]^{2} d t \\
& -\int_{0}^{T} e^{G(t)} F(t, u(t)) d t \\
& -\sum_{j=1}^{n} e^{G\left(t_{j}\right)} \int_{0}^{u\left(t_{j}\right)} I_{j}(t) d t \\
& \leq \frac{M}{2} \sum_{i=1}^{k} c_{i}^{2} \int_{0}^{T}\left[\varphi_{i}^{\prime}(t)\right]^{2} d t \\
& -\frac{m \lambda}{2} \sum_{i=1}^{k} c_{i}^{2} \int_{0}^{T}\left[\varphi_{i}(t)\right]^{2} d t \\
& -\int_{0}^{T} e^{G(t)} F(t, u(t)) d t-\sum_{j=1}^{n} e^{G\left(t_{j}\right)} \int_{0}^{u\left(t_{j}\right)} I_{j}(t) d t \\
& =\frac{1}{2} \sum_{i=1}^{k} c_{i}^{2}\left(M-\frac{m \lambda}{\lambda_{i}}\right)-\int_{0}^{T} e^{G(t)} F(t, u(t)) d t \\
& -\sum_{j=1}^{n} e^{G\left(t_{j}\right)} \int_{0}^{u\left(t_{j}\right)} I_{j}(t) d t \\
& \leq \frac{1}{2}\left(M-\frac{m \lambda}{\lambda_{k}}\right) c^{2}+o\left(c^{2}\right)+o\left(c^{2}\right),
\end{aligned}
$$

for small $c>0$. Since $\lambda \in\left(M \lambda_{k} / m, r\right], E_{1}(u)<0$ and the proof is complete.
Theorem 5. Suppose that the following conditions hold.

(H1) There exist $u_{1}>0, r>M \lambda_{k} / m, \lambda_{k}$ which is the kth eigenvalue of (7) such that

$$
\begin{array}{r}
r M u_{1}+e^{G(t)} f\left(t, u_{1}\right)=0, \quad r M u_{1}+e^{G(t)} f(t, u)>0 \\
\text { for every } u \in\left(0, u_{1}\right) .
\end{array}
$$

(H2) $\int_{0}^{u} I_{j}(s) d s \leq 0$ for any $u \in R(j=1,2, \ldots, n)$.

(H3) $f(t, u)$ and $I_{j}(u)(j=1,2, \ldots, n)$ are odd about $u$.

(H4) $f(t, u)=o(|u|), I_{j}(u)=o(|u|)$, as $|u| \rightarrow 0, j=$ $1,2, \ldots, n$.

Then, for $\lambda \in\left(M \lambda_{k} / m, r\right]$, problem (1) has at least $k$ distinct pairs of solutions.

Proof. The proof is similar to the proof of Theorem 4, and therefore we omit it.

Theorem 6. Suppose that the following conditions hold.

(H1) There exist $u_{2}>0, r>M \lambda_{k} / m, \lambda_{k}$ which is the kth eigenvalue of (7) such that

$$
\begin{array}{r}
r M u_{2}+e^{G(t)} f\left(t, u_{2}\right) \leq 0, \quad I_{j}\left(u_{2}\right) \leq 0, \\
j=1,2, \ldots, n .
\end{array}
$$

(H2) $f(t, u)$ and $I_{j}(u)(j=1,2, \ldots, n)$ are odd about $u$.

(H3) $f(t, u)=o(|u|), I_{j}(u)=o(|u|)$, as $|u| \rightarrow 0, j=$ $1,2, \ldots, n$.

Then, for $\lambda \in\left(M \lambda_{k} / m, r\right]$, problem (1) has at least $k$ distinct pairs of solutions.

Proof. Set

$$
\begin{gathered}
h_{2}(\lambda, t, u)= \begin{cases}\lambda e^{G(t)} u+e^{G(t)} f(t, u), & u \in\left[-u_{2}, u_{2}\right], \\
\lambda e^{G(t)} u_{2}+e^{G(t)} f\left(t, u_{2}\right), & u \in\left[u_{2},+\infty\right), \\
-\lambda e^{G(t)} u_{2}-e^{G(t)} f\left(t,-u_{2}\right), & u \in\left(-\infty,-u_{2}\right],\end{cases} \\
T_{j}(u)= \begin{cases}I_{j}(u), & u \in\left[-u_{2}, u_{2}\right], \\
I_{j}\left(u_{2}\right), & u \in\left[u_{2},+\infty\right), \\
I_{j}\left(-u_{2}\right), & u \in\left(-\infty,-u_{2}\right] .\end{cases}
\end{gathered}
$$

Consider

$$
\begin{gathered}
-\left(e^{G(t)} u^{\prime}(t)\right)^{\prime}=h_{2}(\lambda, t, u(t)), \\
t \neq t_{j}, \quad \text { a.e. } t \in[0, T], \\
-\Delta u^{\prime}\left(t_{j}\right)=T_{j}\left(u\left(t_{j}\right)\right), \quad j=1,2, \ldots, n, \\
u^{\prime}(0)=0, u(T)=0 .
\end{gathered}
$$

Next, we will verify that the solutions of problem (41) are solutions of problem (1). 
In fact, let $\omega_{1}=\left\{t \in\left(a_{1}, b_{1}\right) \subseteq[0, T]: u(t)>u_{2}\right\}$. By the definitions of $h_{2}(\lambda, t, u)$ and $T_{j}(u),(41)$ is reduced to

$$
\begin{gathered}
-\left(e^{G(t)} u^{\prime}(t)\right)^{\prime}=h_{2}\left(\lambda, t, u_{2}\right)=\lambda e^{G(t)} u_{2}+e^{G(t)} f\left(t, u_{2}\right) \\
\leq r M u_{2}+e^{G(t)} f\left(t, u_{2}\right) \leq 0, \quad t \neq t_{j}, \quad \text { a.e. } t \in\left(a_{1}, b_{1}\right), \\
-\Delta u^{\prime}\left(t_{j}\right)=T_{j}\left(u\left(t_{j}\right)\right)=I_{j}\left(u_{2}\right) \leq 0, \quad j=1,2, \ldots, n, \\
u\left(a_{1}\right)=u\left(b_{1}\right)=u_{2} .
\end{gathered}
$$

The solution $u(t)$ of (42) satisfies $u(t) \leq u_{2}, t \in\left(a_{1}, b_{1}\right)$. So $\omega_{1}=\emptyset$ and $u(t) \leq u_{2}$.

Let $\omega_{2}=\left\{t \in\left(a_{2}, b_{2}\right) \subseteq[0, T]: u(t)<-u_{2}\right\}$. By the definitions of $h_{2}(\lambda, t, u)$ and $T_{j}(u),(41)$ is reduced to

$$
\begin{gathered}
-\left(e^{G(t)} u^{\prime}(t)\right)^{\prime}=h_{2}\left(\lambda, t,-u_{2}\right)=-\lambda e^{G(t)} u_{2}+e^{G(t)} f\left(t,-u_{2}\right) \\
\geq-r M u_{2}-e^{G(t)} f\left(t, u_{2}\right) \geq 0, \\
t \neq t_{j}, \quad \text { a.e. } t \in\left(a_{2}, b_{2}\right), \\
-\Delta u^{\prime}\left(t_{j}\right)=T_{j}\left(u\left(t_{j}\right)\right)=-I_{j}\left(u_{2}\right) \geq 0, \quad j=1,2, \ldots, n, \\
u\left(a_{2}\right)=u\left(b_{2}\right)=-u_{2} .
\end{gathered}
$$

The solution $u(t)$ of (43) satisfies $u(t) \geq-u_{2}, t \in\left(a_{2}, b_{2}\right)$. So $\omega_{2}=\emptyset$ and $u(t) \geq-u_{2}$.

Therefore, the solutions of (41) are solutions of (1). Hence to prove Theorem 6 , it suffices to produce at least $k$ distinct pairs of critical points of

$$
\begin{aligned}
E_{2}(u)= & \frac{1}{2} \int_{0}^{T} e^{G(t)}\left|u^{\prime}(t)\right|^{2} d t-\int_{0}^{T} H_{2}(\lambda, t, u(t)) d t \\
& -\sum_{j=1}^{n} e^{G\left(t_{j}\right)} \int_{0}^{u\left(t_{j}\right)} T_{j}(t) d t,
\end{aligned}
$$

where $H_{2}(\lambda, t, u(t))=\int_{0}^{u} h_{2}(\lambda, t, s) d s$.

We will apply Lemma 3 to finish the proof.

By (44) and (H2), $E_{2} \in C^{\prime}(X, R)$ is even and $E_{2}(0)=0$.

Next, we will show that $E_{2}$ is bounded from below.

By (H1) and (H2), we have $u h_{2}(\lambda, t, u(t)) \leq 0$ and $u T_{j}(u) \leq 0$ for $|u| \geq u_{2}$; thus

$$
\begin{aligned}
& \int_{0}^{T} H_{2}(\lambda, t, u(t)) d t=\int_{0}^{T} \int_{0}^{u(t)} h_{2}(\lambda, t, s) d s d t \\
& \leq \int_{0}^{T} \int_{0}^{u_{2}} h_{2}(\lambda, t, s) d s d t \\
& \leq \int_{0}^{T} \int_{0}^{u_{2}}[r M s+f(t, s)] d s d t=\rho>0 \\
& \int_{0}^{u\left(t_{j}\right)} T_{j}(t) d t \leq \int_{0}^{u_{2}} T_{j}(t) d t=\delta>0 .
\end{aligned}
$$

So, we have

$$
\begin{aligned}
E_{2}(u)= & \frac{1}{2}\|u\|^{2}-\int_{0}^{T} H_{2}(\lambda, t, u(t)) d t \\
& -\sum_{j=1}^{n} e^{G\left(t_{j}\right)} \int_{0}^{u\left(t_{j}\right)} T_{j}(t) d t \\
\geq & \frac{1}{2}\|u\|^{2}-\rho-n M \delta \\
> & -\infty
\end{aligned}
$$

for any $u \in X$. Therefore, $E_{2}$ is bounded from below.

In the following we will show that $E_{2}$ satisfies the P.S. condition. Let $\left\{u_{k}\right\} \subset X$ such that $\left\{E_{2}\left(u_{k}\right)\right\}$ is a bounded sequence and $\lim _{k \rightarrow \infty} E_{2}^{\prime}\left(u_{k}\right)=0$; then there exists $C_{4}>0$ such that

$$
\left|E_{2}\left(u_{k}\right)\right| \leq C_{4}
$$

By (46), we have

$$
\frac{1}{2}\left\|u_{k}\right\|^{2} \leq C_{4}+\rho+n M \delta
$$

So $\left\{u_{k}\right\}$ is bounded in $X$. From the reflexivity of $X$, we may extract a weakly convergent subsequence that, for simplicity, we call $\left\{u_{k}\right\}, u_{k} \rightarrow u$ in $X$. In the following we will verify that $\left\{u_{k}\right\}$ strongly converges to $u$ :

$$
\begin{aligned}
& \left(E_{2}^{\prime}\left(u_{k}\right)-E_{2}^{\prime}(u)\right)\left(u_{k}-u\right) \\
& =\left\|u_{k}-u\right\|^{2}-\int_{0}^{T}\left[h_{2}\left(\lambda, t, u_{k}(t)\right)-h_{2}(\lambda, t, u(t))\right] \\
& \quad \times\left(u_{k}(t)-u(t)\right) d t \\
& +\sum_{j=1}^{n} e^{G\left(t_{j}\right)}\left[T_{j}\left(u_{k}\left(t_{j}\right)\right)-T_{j}\left(u\left(t_{j}\right)\right)\right] \\
& \quad \times\left(u_{k}\left(t_{j}\right)-u\left(t_{j}\right)\right) .
\end{aligned}
$$

By $u_{k} \rightarrow u$ in $X$, we see that $\left\{u_{k}\right\}$ uniformly converges to $u$ in $C[0, T]$. So

$$
\begin{gathered}
\int_{0}^{T}\left[h_{2}\left(\lambda, t, u_{k}(t)\right)-h_{2}(\lambda, t, u(t))\right]\left(u_{k}(t)-u(t)\right) d t \rightarrow 0, \\
\sum_{j=1}^{n} e^{G\left(t_{j}\right)}\left[T_{j}\left(u_{k}\left(t_{j}\right)\right)-T_{j}\left(u\left(t_{j}\right)\right)\right]\left(u_{k}\left(t_{j}\right)-u\left(t_{j}\right)\right) \rightarrow 0, \\
\left(E_{2}^{\prime}\left(u_{k}\right)-E_{2}^{\prime}(u)\right)\left(u_{k}-u\right) \rightarrow 0, \quad \text { as } k \longrightarrow+\infty .
\end{gathered}
$$

So we obtain $\left\|u_{k}-u\right\| \rightarrow 0$, as $k \rightarrow+\infty$. That is, $\left\{u_{k}\right\}$ strongly converges to $u$ in $X$, which means $E_{2}$ satisfies the P.S. condition.

Now set $K=\left\{\sum_{i=1}^{k} c_{i} \varphi_{i}: \sum_{i=1}^{k} c_{i}^{2}=c^{2}\right\}$, where $\varphi_{i}$ is defined in (9). It is clear that $K$ is homeomorphic to $S^{k-1}$ by an odd 
map for any $c>0$. In the following we verify that $\left.E_{2}\right|_{K}<0$ if $c$ is sufficiently small.

For any $u \in K, u=\sum_{i=1}^{k} c_{i} \varphi_{i}$. By (H3) and (44), we have

$$
\begin{aligned}
& E_{2}(u)=\frac{1}{2} \int_{0}^{T} e^{G(t)}\left[\left(\sum_{i=1}^{k} c_{i} \varphi_{i}(t)\right)^{\prime}\right]^{2} d t \\
& -\int_{0}^{T} H_{2}(\lambda, t, u(t)) d t \\
& -\sum_{j=1}^{n} e^{G\left(t_{j}\right)} \int_{0}^{u\left(t_{j}\right)} T_{j}(t) d t \\
& =\frac{1}{2} \sum_{i=1}^{k} c_{i}^{2} \int_{0}^{T} e^{G(t)}\left[\varphi_{i}^{\prime}(t)\right]^{2} d t \\
& -\frac{\lambda}{2} \sum_{i=1}^{k} c_{i}^{2} \int_{0}^{T} e^{G(t)}\left[\varphi_{i}(t)\right]^{2} d t \\
& -\int_{0}^{T} e^{G(t)} F(t, u(t)) d t \\
& -\sum_{j=1}^{n} e^{G\left(t_{j}\right)} \int_{0}^{u\left(t_{j}\right)} T_{j}(t) d t \\
& \leq \frac{M}{2} \sum_{i=1}^{k} c_{i}^{2} \int_{0}^{T}\left[\varphi_{i}^{\prime}(t)\right]^{2} d t-\frac{m \lambda}{2} \sum_{i=1}^{k} c_{i}^{2} \int_{0}^{T}\left[\varphi_{i}(t)\right]^{2} d t \\
& -\int_{0}^{T} e^{G(t)} F(t, u(t)) d t-\sum_{j=1}^{n} e^{G\left(t_{j}\right)} \int_{0}^{u\left(t_{j}\right)} T_{j}(t) d t \\
& =\frac{1}{2} \sum_{i=1}^{k} c_{i}^{2}\left(M-\frac{m \lambda}{\lambda_{i}}\right)-\int_{0}^{T} e^{G(t)} F(t, u(t)) d t \\
& -\sum_{j=1}^{n} e^{G\left(t_{j}\right)} \int_{0}^{u\left(t_{j}\right)} T_{j}(t) d t \\
& \leq \frac{1}{2}\left(M-\frac{m \lambda}{\lambda_{k}}\right) c^{2}+o\left(c^{2}\right)+o\left(c^{2}\right),
\end{aligned}
$$

for small $c>0$. Since $\lambda \in\left(M \lambda_{k} / m, r\right], E_{2}(u)<0$ and the proof is complete.

\section{Example}

To illustrate how our main results can be used in practice we present the following example.

Example 1. Let $T=\pi / 4, g(t)=-2 t$, and consider the following problem:

$$
\begin{aligned}
& -u^{\prime \prime}(t)-2 t u^{\prime}(t)-\lambda u(t) \\
& =(1+t)\left(u-u^{2}\right)-1000 e^{\left(\pi^{2} / 16\right)-t^{2}}, \quad t \in\left[0, \frac{\pi}{4}\right], t \neq t_{j},
\end{aligned}
$$

$$
\begin{gathered}
-\Delta u^{\prime}\left(t_{j}\right)=2-\sqrt[3]{u\left(t_{j}\right)}, \quad j=1,2, \ldots, n, \\
u^{\prime}(0)=0, \quad u\left(\frac{\pi}{4}\right)=0 .
\end{gathered}
$$

Compared with (1), $f(t, u)=(1+t)\left(u-u^{2}\right)-$ $1000 e^{\left(\pi^{2} / 16\right)-t^{2}}, I_{j}(u)=2-\sqrt[3]{u(t)}$. Obviously (H2), (H3), and (H4) are satisfied. Let $u_{1}=1, r=1000$; then (H1) is satisfied. By Theorem 4 , for $\left(M \lambda_{k} / m, 1000\right]=\left(4 e^{\pi^{2} / 16}(2 k-\right.$ $\left.1)^{2} \pi^{2}, 1000\right], k=1,2$, problem (1) has at least $k$ distinct pairs of solutions.

Example 2. Let $T=\pi / 2, g(t)=-t / 4$, and consider the following problem:

$$
\begin{aligned}
& -u^{\prime \prime}(t)-\frac{t}{4} u^{\prime}(t)-\lambda u(t) \\
& =\left(1+t^{2}\right)\left(2 u-u^{2}\right)-1000 e^{\left(\pi^{2} / 32\right)-t^{2}}, \\
& t \in\left[0, \frac{\pi}{2}\right], t \neq t_{j}, \\
& -\Delta u^{\prime}\left(t_{j}\right)=-u\left(t_{j}\right), \quad j=1,2, \ldots, n, \\
& u^{\prime}(0)=0, \quad u\left(\frac{\pi}{2}\right)=0 .
\end{aligned}
$$

Compared with (1), $f(t, u)=\left(1+t^{2}\right)\left(2 u-u^{2}\right)-$ $1000 e^{\left(\pi^{2} / 32\right)-t^{2}}, I_{j}(u)=-u\left(t_{j}\right)$. Obviously (H2), (H3), and (H4) are satisfied. Let $u_{1}=2, r=500$; then (H1) is satisfied. By Theorem 5, for $\left(M \lambda_{k} / m, 500\right]=\left(e^{\pi^{2} / 32}(2 k-1)^{2} \pi^{2}, 500\right]$, $k=1,2,3,4$, problem (53) has at least $k$ distinct pairs of solutions.

Example 3. Let $T=\pi / 2, g(t)=-t / 2$, and consider the following problem:

$$
\begin{gathered}
-u^{\prime \prime}(t)-\frac{t}{2} u^{\prime}(t)-\lambda u(t) \\
=-e^{\pi^{2} / 16}\left(1+t^{2}\right) u^{3}(t), \quad t \in\left[0, \frac{\pi}{2}\right], t \neq t_{j}, \\
-\Delta u^{\prime}\left(t_{j}\right)=-3 u^{3}\left(t_{j}\right), \quad j=1,2, \ldots, n, \\
u^{\prime}(0)=0, \quad u\left(\frac{\pi}{2}\right)=0 .
\end{gathered}
$$

Compared with (1), $f(t, u)=-e^{\pi^{2} / 16}\left(1+t^{2}\right) u^{3}(t), I_{j}(u)=$ $-3 u^{3}\left(t_{j}\right)$. Obviously $(\mathrm{H} 2)$ and $(\mathrm{H} 3)$ are satisfied. Let $u_{2}=$ $25, r=625$; then $(\mathrm{H} 1)$ is satisfied. By Theorem 6, for $\left(M \lambda_{k} / m, 625\right]=\left(e^{\pi^{2} / 16}(2 k-1)^{2} \pi^{2}, 625\right], k=1,2,3$, problem (54) has at least $k$ distinct pairs of solutions.

\section{Conflict of Interests}

The authors declare that there is no conflict of interests regarding the publication of this paper. 


\section{Acknowledgments}

This work is partially supported by the National Natural Science Foundation of China (no. 71201013) and the Innovation Platform Open Funds for Universities in Hunan Province (no. 13K059).

\section{References}

[1] M. Benchohra, J. Henderson, and S. Ntouyas, Impulsive Differential Equations and Inclusions, vol. 2 of Contemporary Mathematics and Its Applications, Hindawi Publishing Corporation, New York, NY, USA, 2006.

[2] A. M. Samoullenko and N. A. Perestyuk, Impulsive Differential Equations, vol. 14, World Scientific, River Edge, NJ, USA, 1995.

[3] R. P. Agarwal, D. Franco, and D. O'Regan, "Singular boundary value problems for first and second order impulsive differential equations," Aequationes Mathematicae, vol. 69, no. 1-2, pp. 8396, 2005.

[4] J. J. Nieto, "Impulsive resonance periodic problems of first order," Applied Mathematics Letters, vol. 15, no. 4, pp. 489-493, 2002.

[5] L. Yu, S. Wang, F. Wen, K. K. Lai, and S. He, "Designing a hybrid intelligent mining system for credit risk evaluation," Journal of Systems Science \& Complexity, vol. 21, no. 4, pp. 527-539, 2008.

[6] Z. Luo and J. Shen, "Stability and boundedness for impulsive functional differential equations with infinite delays," Nonlinear Analysis: Theory, Methods \& Applications, vol. 46, no. 4, pp. 475493, 2001.

[7] M. Choisy, J.-F. Guégan, and P. Rohani, "Dynamics of infectious diseases and pulse vaccination: teasing apart the embedded resonance effects," Physica D, vol. 223, no. 1, pp. 26-35, 2006.

[8] J. Jiao, X. Yang, L. Chen, and S. Cai, "Effect of delayed response in growth on the dynamics of a chemostat model with impulsive input," Chaos, Solitons and Fractals, vol. 42, no. 4, pp. 2280-2287, 2009.

[9] C. Huang, C. Peng, X. Chen, and F. Wen, "Dynamics analysis of a class of delayed economic model," Abstract and Applied Analysis, vol. 2013, Article ID 962738, 12 pages, 2013.

[10] G. Zeng, F. Wang, and J. J. Nieto, "Complexity of a delayed predator-prey model with impulsive harvest and Holling type II functional response," Advances in Complex Systems, vol. 11, no. 1, pp. 77-97, 2008.

[11] Z. Dai and F. Wen, "Another improved Wei-Yao-Liu nonlinear conjugate gradient method with sufficient descent property," Applied Mathematics and Computation, vol. 218, no. 14, pp. 74217430, 2012.

[12] J. Shen and W. Wang, "Impulsive boundary value problems with nonlinear boundary conditions," Nonlinear Analysis: Theory, Methods \& Applications, vol. 69, no. 11, pp. 4055-4062, 2008.

[13] E. K. Lee and Y.-H. Lee, "Multiple positive solutions of singular two point boundary value problems for second order impulsive differential equations," Applied Mathematics and Computation, vol. 158, no. 3, pp. 745-759, 2004.

[14] Y. Zhao and H. Chen, "Multiplicity of solutions to twopoint boundary value problems for second-order impulsive differential equations," Applied Mathematics and Computation, vol. 206, no. 2, pp. 925-931, 2008.

[15] Z.-G. Wang, G.-W. Zhang, and F.-H. Wen, "Properties and characteristics of the Srivastava-Khairnar-More integral operator," Applied Mathematics and Computation, vol. 218, no. 15, pp. 7747-7758, 2012.
[16] J. J. Nieto and D. O’Regan, "Variational approach to impulsive differential equations," Nonlinear Analysis: Real World Applications, vol. 10, no. 2, pp. 680-690, 2009.

[17] L. Yan, J. Liu, and Z. Luo, "Existence of solution for impulsive differential equations with nonlinear derivative dependence via variational methods," Abstract and Applied Analysis, vol. 2013, Article ID 908062, 10 pages, 2013.

[18] L. Z. Yan, J. Liu, and Z. G. Luo, "Existence and multiplicity of solutions for second-order impulsive differential equations on the half-line," Advances in Difference Equations, vol. 2013, article 293, 2013.

[19] Z. Zhang and R. Yuan, "An application of variational methods to Dirichlet boundary value problem with impulses," Nonlinear Analysis: Real World Applications, vol. 11, no. 1, pp. 155-162, 2010.

[20] J. Xie and Z. Luo, "Existence of three distinct solutions to boundary value problems of nonlinear differential equations with a $p$-Laplacian operator," Applied Mathematics Letters, vol. 27, pp. 101-106, 2014.

[21] J. Mawhin and M. Willem, Critical Point Theory and Hamiltonian Systems, vol. 74, Springer, New York, NY, USA, 1989.

[22] J. J. Nieto, "Variational formulation of a damped Dirichlet impulsive problem," Applied Mathematics Letters, vol. 23, no. 8, pp. 940-942, 2010.

[23] J. Xiao and J. J. Nieto, "Variational approach to some damped Dirichlet nonlinear impulsive differential equations," Journal of the Franklin Institute, vol. 348, no. 2, pp. 369-377, 2011.

[24] P. H. Rabinowitz, Minimax Methods in Critical Point Theory with Applications to Differential Equations, vol. 65 of CBMS Regional Conference Series in Mathematics, American Mathematical Society, Providence, RI, USA, 1986. 


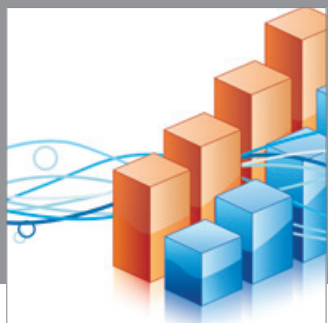

Advances in

Operations Research

mansans

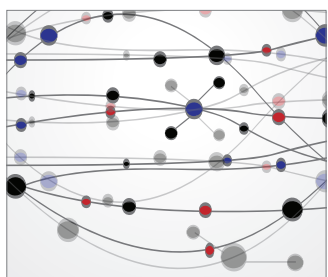

The Scientific World Journal
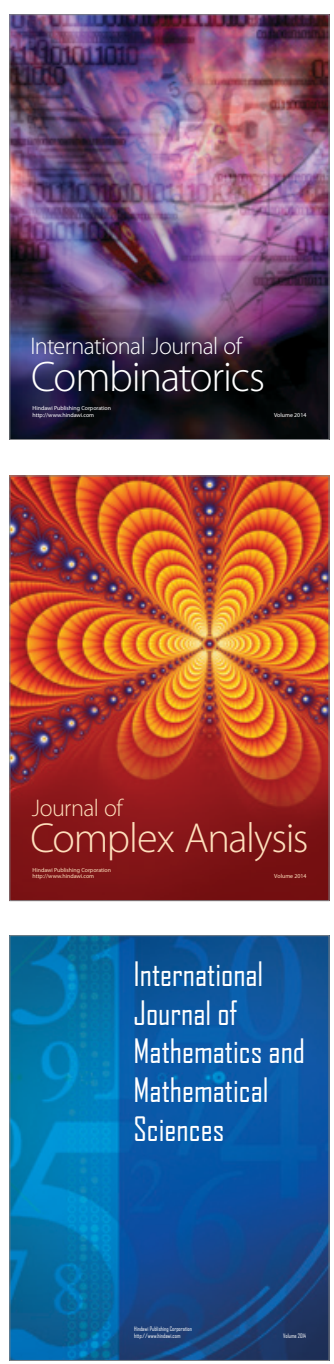
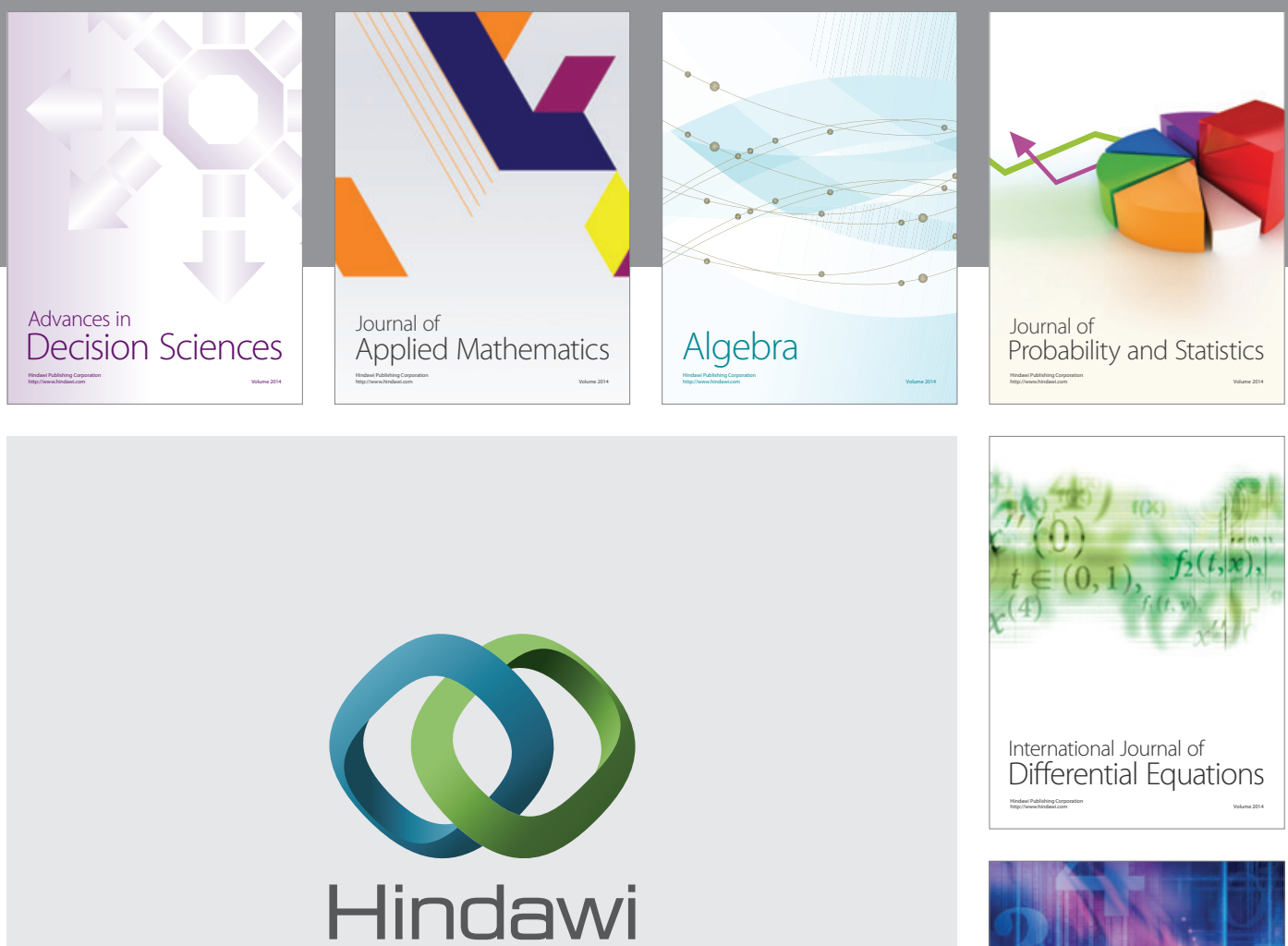

Submit your manuscripts at http://www.hindawi.com
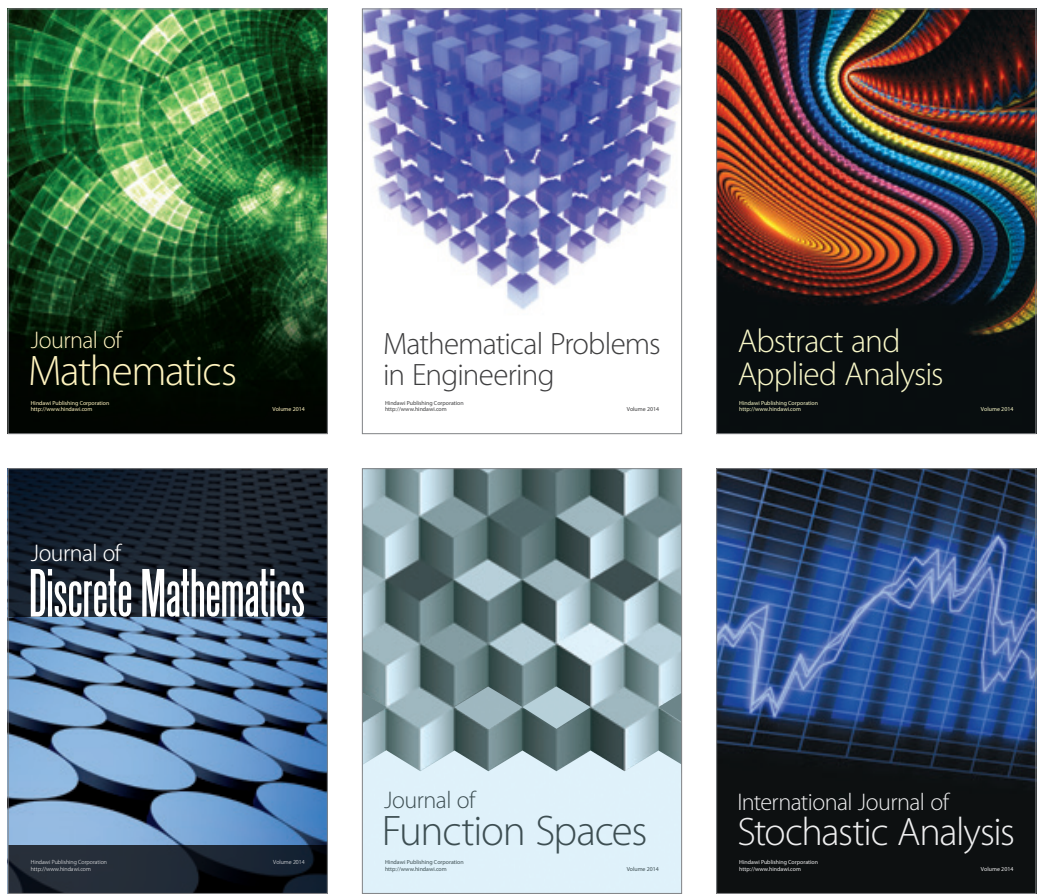

Journal of

Function Spaces

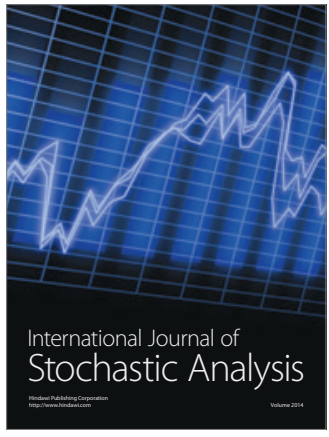

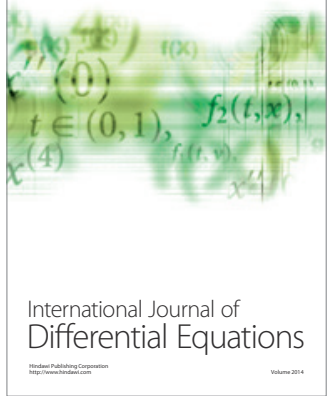
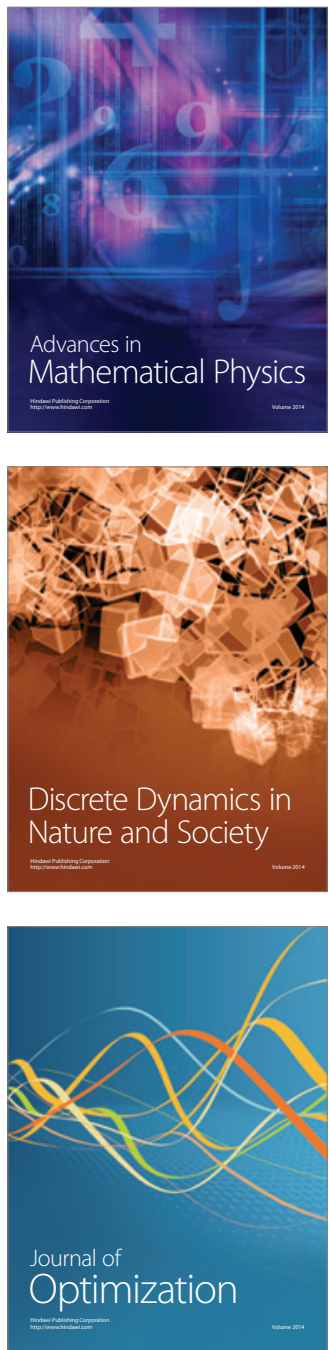